Mikrochimica Acta [Wien] 1972, 303-312

(C) by Springer-Verlag 1972

Twente University of Technology, Department of Chemistry, P. O. Box 217, Enschede, The Netherlands

\title{
Application of Ion-selective Electrodes for the Microdetermination of Chlorine and Bromine in Volatile Organic Compounds
}

\author{
Вy \\ W. Potman and E. A. M. F. Dahmen \\ With 7 Figures
}

(Received August 10, 1971)

The results for the microdetermination of chlorine and bromine in highly halogenated volatile organic compounds with the oxygen flask method according to Schöniger are in many instances too low, because of incomplete combustion ${ }^{1,2}$. Several types of container for liquids have been used in the Schöniger method ${ }^{1,3,4}$. The use of thin polyethylene tubing is preferable to adhesive cellulose tape; the adhesive on the cellulose tape has a tendency to dissolve in the sample, resulting in a loss of the latter. Commercially available capsules (methyl cellulose, cellulose acetate and gelatin) have been found to have variable halogen blank values and their volume is too large for microanalysis.

Milligram samples of highly halogenated volatile compounds can be analysed by combustion tube method ${ }^{2,5-7}$. In each of these methods the final analysis is carried out in a step separate from the combustion.

Krijgsman et al. 8 have described a semi-automatic potentiometric method for organic halogen determination. The halide in the combustion gases is absorbed in $80 \%$ acetic acid and titrated with silver in the presence of an ion-selective $\mathrm{Ag}_{2} \mathrm{~S}$ electrode. A previously selected potential is taken for both the starting point and end-point of the titration. It was found, however, that the number of milligram samples which could be determined consecutively was limited because silver halide precipitates were formed; when about $18 \mu \mathrm{eq}$ of chloride or bromide had been titrated, 
adsorption of the halide on the precipitate occurred and low results were obtained; addition of tetraethylammonium perchlorate to the absorption solution did not fully prevent this co-precipitation.

An ion-selective $\mathrm{Ag}_{2} \mathrm{~S}$ electrode has also been applied by $S w a r t z$ and Light ${ }^{9}$ to the determination of $\mathrm{S}^{2-}$ and by Papp and Havas ${ }^{10}$ for the determination of $\mathrm{S}^{2-}, \mathrm{S}_{2} \mathrm{O}_{3}{ }^{2-}$ and $\mathrm{SO}_{3}{ }^{2-}$; these authors used $\mathrm{Hg}^{2+}$ as titrant. Although the mechanism of the reaction of $\mathrm{Hg}^{2+}$ ions with the $\mathrm{Ag}_{2} \mathrm{~S}$ electrode is not fully clear, titrations of halides with $\mathrm{Hg}^{2+}$ have advantages over those with $\mathrm{Ag}^{+}$because $\mathrm{Hg}^{2+}$ ions form strong and soluble complexes with halides.

\section{Experimental}

\section{Principle of the Determination}

The sample is introduced by injection. After the combustion in an oxygen atmosphere over quartz and platinum at $1000^{\circ}$, the halide is absorbed in $80 \%$ acetic acid containing some nitric acid, hydrogen peroxide and mercuric chloride or bromide.

The titration is carried out with $\mathrm{Hg}^{2+}$. A selected potential between the reference and ion-selective electrodes is taken as both starting point and end-point for the titration.

\section{Reagents}

Absorption solution: a mixture of $80 \%$ acetic acid, $1.5 \%$ nitric acid, $1.2 \%$ hydrogen peroxide and $17.3 \%$ water, all $v / v$, plus $140 \mathrm{mg}$ of $\mathrm{HgCl}_{2}$ or $\mathrm{HgBr}_{2}$ per $100 \mathrm{ml}$. This solution is kept in the dark.

$\mathrm{Hg}^{2+}$ solution, $0.1 \mathrm{~N}: 1.085 \mathrm{~g}$ of $\mathrm{HgO}$ dissolved in $100 \mathrm{ml}$ of a mixture containing $80 \%$ acetic acid, $5 \%$ nitric acid and $15 \%$ water, all $v / v$. All reagents are analytical-reagent grade.

\section{Apparatus}

Fig. 1 shows a scheme of the apparatus used for combustion and titration. The sample is injected by way of septum $I$ (Dohrmann 523-728). The injection port 2 (110 $\mathrm{mm}$ long, o. d. $10.5 \mathrm{~mm}$ ), which is surrounded by a heating tape, contains an inner tube $(73 \mathrm{~mm}$ long, o.d. $6.5 \mathrm{~mm})$ filled with quartz wool. The combustion tube is completed by parts 3 ( $145 \mathrm{~mm}$ long, o. d. $22 \mathrm{~mm}$ ) and $4(80 \mathrm{~mm}$ long, o. d. $10.5 \mathrm{~mm})$, the latter provided with a glass joint NS 7/16. The combustion tube is connected by means of a $2-\mathrm{mm}$ capillary, surrounded by a heating tape 5 , to a cylindrical water-cooled absorption vessel ${ }^{11}$ via a three-way stop-cock ( $2 \mathrm{~mm}$ bore). The double-junction reference electrode and the ion-specific electrode are placed in $6(80 \mathrm{~mm}$ long, o.d. $12 \mathrm{~mm}$ ) and 7 (85 mm long and o. d. $28 \mathrm{~mm})$, respectively. Tube $8(38 \mathrm{~mm}$ long, o.d. $8 \mathrm{~mm}$ ) is located at the centre of chamber 9 (height $13 \mathrm{~mm}$, o.d. $40 \mathrm{~mm}$ ) which contains a Teflon-covered magnetic stirrer (22 $\mathrm{mm}$ long, o. d. $17 \mathrm{~mm}$ ). The end of the $2-\mathrm{mm}$ capillary, surrounded by a short piece of PVC tubing, is connected to the absorption vessel. All parts are made from Pyrex glass except for the quartz combustion tube. A 20-mm length 
in the centre of the combustion tube is filled with platinum-quartz wool (Heraeus). Quartz granules are placed on each side as indicated in Fig. 1. The combustion tube was heated at $1000^{\circ}$ by a Hereaus Rok 3/30 furnace (10). The titrant was added from a $600-\mu \mathrm{l}$ burette (Ströhlein) through a polyethylene

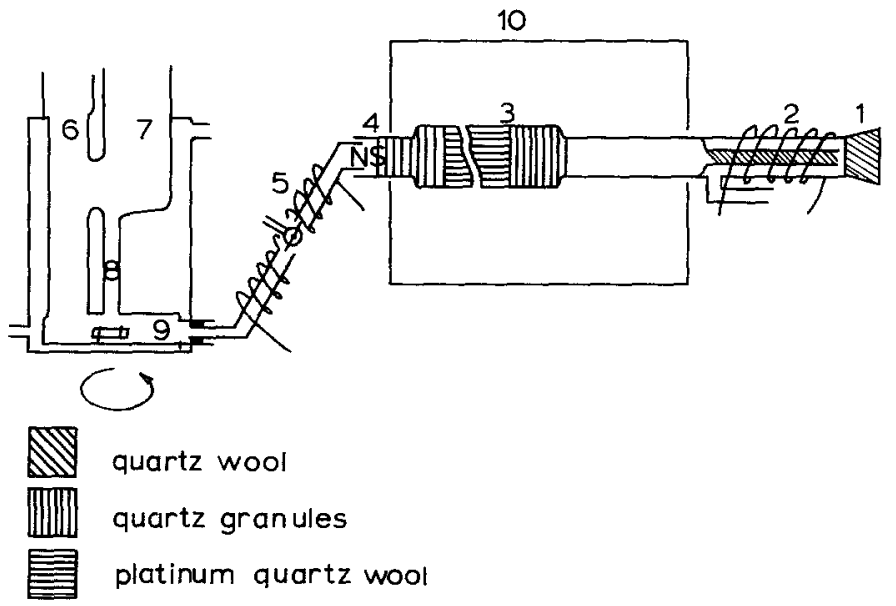

Fig. 1. Combustion and titration apparaturs

capillary, the tip of which must be placed in tube 8 well below the electrode crystal surface. The $\mathrm{mV}$ readings were made on a Knick $\mathrm{PH}_{\mathrm{H}}$-meter, range $140 \mathrm{mV}$, connected to a Kipp flat-bed recorder.

Electrodes: $\mathrm{Ag}_{2} \mathrm{~S}$ electrode (Orion 94-16); AgI electrode (Philips IS 550-I); Double-junction Ag/AgCI ref. electrode (Ingold 373-90-M 5 NS).

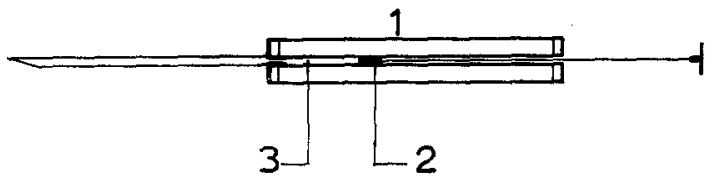

Fig. 2. Light-weight hypodermic syringe

Hypodermic syringe: a 10- $1 \mathrm{I}$ syringe was used (Precision Sampling Corp., Baton Rouge, Louisiana). This syringe can be weighed to within $10 \mu \mathrm{g}$ if gloves are used. A small hypodermic syringe (Fig. 2) was designed so that weighings to $1 \mu \mathrm{g}$ could be made. It consists of a glass tube $1(4.0 \mathrm{~mm}$ long, o. d. $3.5 \mathrm{~mm}$ ) in which a capillary tube $2(\mathrm{i} . \mathrm{d} .0 .5 \mathrm{~mm}$, o. d. $1 \mathrm{~mm}$ ) is centrally held. The piston is made from stainless steel and is provided with a Teflon tip 3 and an aluminium handle. A platinum needle (Hamilton KF $726 \mathrm{Pt}$, length outside the syringe $37 \mathrm{~mm}$ ) is fixed in the capillary by means of Araldite. The syringe weighs about $0.8 \mathrm{~g}$. In order to prevent loss of sample during transport and weighing, it is necessary that the sample be held in the glass capillary. 


\section{Procedure}

Adjust the oxygen flow to about $10 \mathrm{ml} / \mathrm{min}$. Turn the three-way stop-cock so that oxygen flows into the atmosphere, and fill the absorption vessel, which is cooled with tap water, with $25 \mathrm{ml}$ of the absorption solution. Place both electrodes in the vessel and pass oxygen into it. Regulate the magnetic stirrer to give a fast circulation of the solution in the vessel and warm up heating tape 5 to $280^{\circ}$. After $15-30$ minutes a constant potential of about $270 \mathrm{mV}$, which is taken as a set-point for the titration, is reached. Inject the sample into the quartz wool in front of tube 2 and warm its heating tape to about $130^{\circ}$. As soon as the halide enters the titration vessel the potential decreases. Add $\mathrm{Hg}^{2+}$ from the burette so that during the titration the potential is held to within $\pm 10 \mathrm{mV}$ of the set-point. In this way the equilibrium potential will be reached more quickly. The titration is complete when not more than $0.1 \mu \mathrm{l}$ of $\mathrm{Hg}^{2+}$ has to be introduced per minute.

\section{Results}

Results of chlorine and bromine determinations in some volatile substances are presented in Table I. Use was made of the light-weight syringe previously described or a $10-\mu \mathrm{l}$ syringe for liquid samples and of a $1000-\mu l$ gas-tight syringe for $\mathrm{CH}_{3} \mathrm{Br}$.

\section{Reversibility of the $A g_{2} S$ and AgI Electrodes with Respect to $\mathrm{Hg}^{2+}$}

The following experiments were done in order to test the reversibility of the $\mathrm{Ag}_{2} \mathrm{~S}$ and $\mathrm{AgI}$ electrodes. $\mathrm{An} \mathrm{Ag}_{2} \mathrm{~S}$ electrode and a double-junction reference electrode were placed in $25 \mathrm{ml}$ of an aqueous solution of nitric acid at $p_{\mathrm{H}} 1$ or 2.7. Increasing quantities of $\mathrm{Hg}^{2+}$ were added and the corresponding potentials measured. Next increasing quantities of EDTA were introduced in order to complex the $\mathrm{Hg}^{2+}$ and the potentials were recorded again. The results are presented in Fig. 3. At $p_{H} 2.7$ the response appears to be reversible to lower $\mathrm{Hg}^{2+}$ concentrations than at $\mathrm{pH}_{\mathrm{H}} \mathbf{l}$. This can be accounted for by the increased stability of the Hg-EDTA complex at $\mathrm{p}_{\mathrm{H}} 2.7$.

The experiment was repeated with the AgI electrode at $\mathrm{p}_{H} 1$ (Fig. 4). Because $\mathrm{Ag}_{2} \mathrm{~S}$ is less soluble than $\mathrm{AgI}, \mathrm{Ag}^{+}$from the $\mathrm{AgI}$ electrode is also available for complexing with EDTA. As a consequence, when the back-titration with EDTA is made an apparently irreversible reaction is observed. Similar measurements were also carried out in $80 \%$ aqueous acetic acid solution. Instead of back-titration of the $\mathrm{Hg}^{2+}$ with EDTA, increasing quantities of $\mathrm{Cl}^{-}$were introduced (Fig. 5).

With the $\mathrm{Ag}_{2} \mathrm{~S}$ electrode measurements were also made in $25 \mathrm{ml}$ of a $95 \%$ aqueous acetic acid solution containing some $\mathrm{HgCl}_{2}$. Increasing 


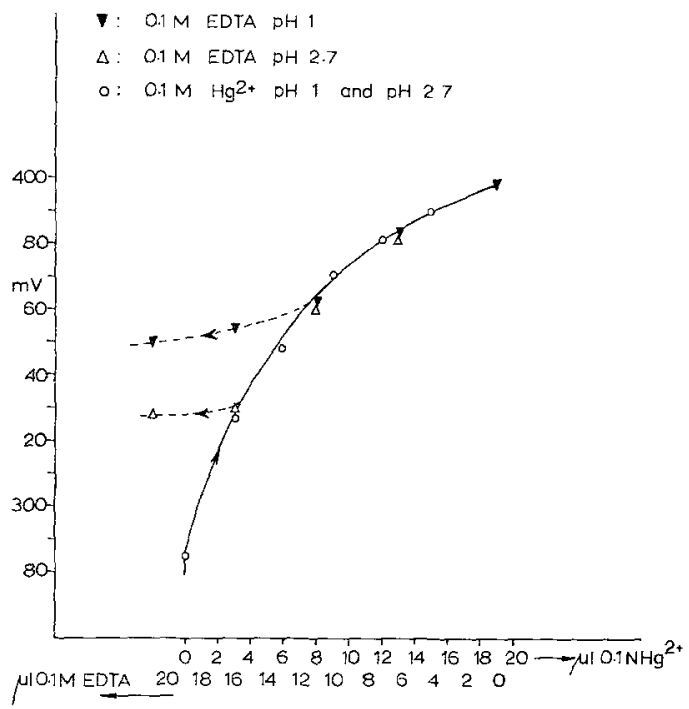

Fig. 3. Reversibility of the $\mathrm{Ag}_{2} \mathrm{~S}$ electrode in dilute nitric acid at pH 1 and $\mathrm{pH} 2.7$ with respect to $\mathrm{Hg}^{2+}$. The $\mathrm{Hg}^{2+}$ is back-titrated with EDTA

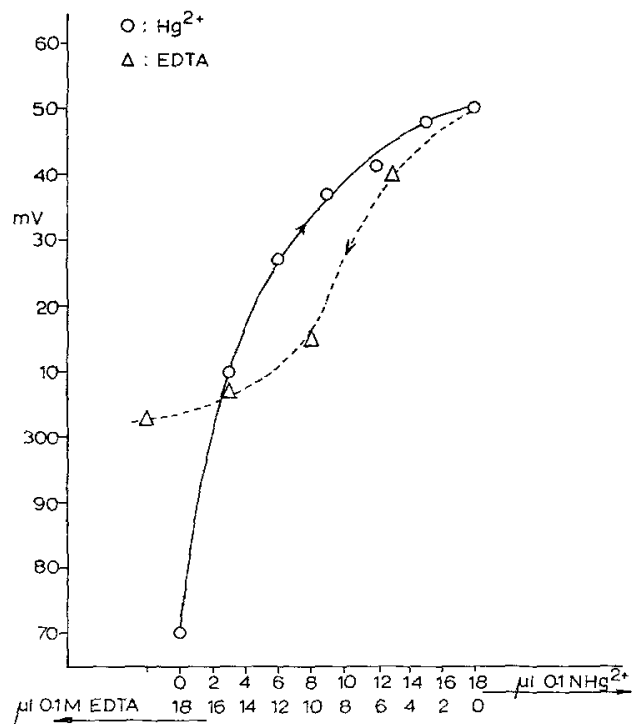

Fig. 4. Irreversibility of the AgI electrode in dilute nitric acid at pH 1 with respect to $\mathrm{Hg}^{2+}$. The $\mathrm{Hg}^{2+}$ is back-titrated with EDTA 
quantities of $\mathrm{Cl}^{-}$and $\mathrm{Br}^{-}$were introduced followed by a back-titration with $\mathrm{Hg}^{2+}$ (Fig. 6). Each experiment was repeated successively. As long as the concentration of $\mathrm{Hg}^{2+}$ is less than $10^{-3} M$ the durability and reversibility of the electrode are unaffected.

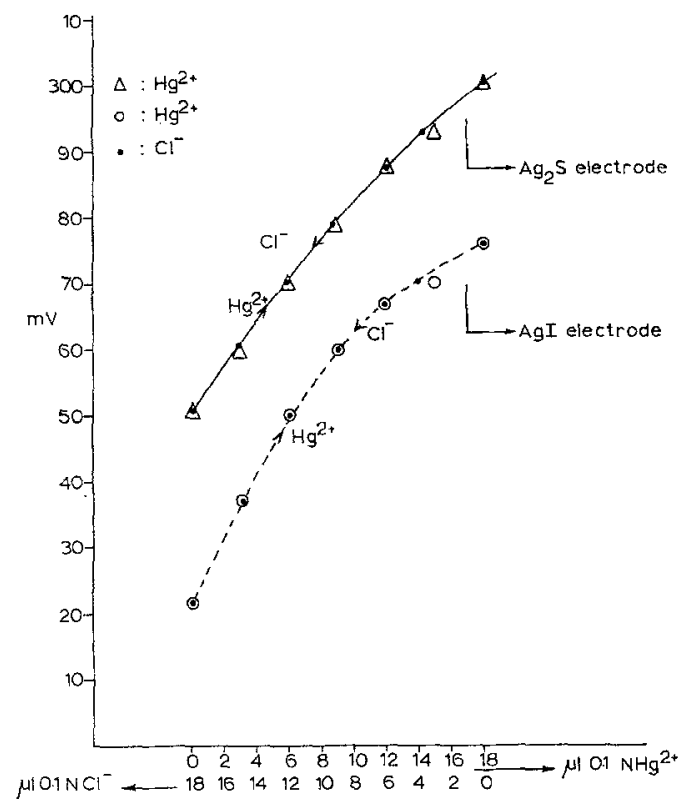

Fig. 5. Reversibility of the $\mathrm{Ag}_{2} \mathrm{~S}$ and $\mathrm{AgI}$ electrode in $80 \%$ acetic acid with respect to $\mathrm{Hg}^{2}$. ${ }^{2}$. 'Lhe $\mathrm{Hg}^{2} ;$ is back-titrated with $\mathrm{Cl}^{-}$

\section{Remarks and Discussion}

The stability of the set-point potential of the titration is dependent on the quantity of water introduced; the latter should remain nearly constant. Therefore, the titrant was also prepared in an $80 \%$ acetic acid medium. The water originating from the sample has no noticeable influence on the measurements. In Fig. 7 is presented the change in the potential as a function of the $\mathrm{HgCl}_{2}$ and $\mathrm{HgBr}_{2}$ concentrations. If at least $30 \mathrm{mg}$ of $\mathrm{HgCl}_{2}$ or $\mathrm{HgBr}_{2}$ are introduced to $25 \mathrm{ml}$ of the absorption solution the potential is scarcely altered. The potential in both solutions is almost identical $(\Delta E$ is $c a .3 \mathrm{mV})$ so the same titration set-point can be used for both the $\mathrm{Cl}^{-}$and $\mathrm{Br}^{-}$determinations.

Introduction of nitric acid to the absorption solution and titrant is necessary to prevent precipitation of $\mathrm{Hg}^{2+}$ salts. It was found that a concentration of $1.5 \% v / v$ and $5 \% v / v$ nitric acid in the absorption solution and titrant respectively prevents this precipitation. With a concentration of $2 \% v / v$ of nitric acid in the titrant, precipitation occurs after two days. 


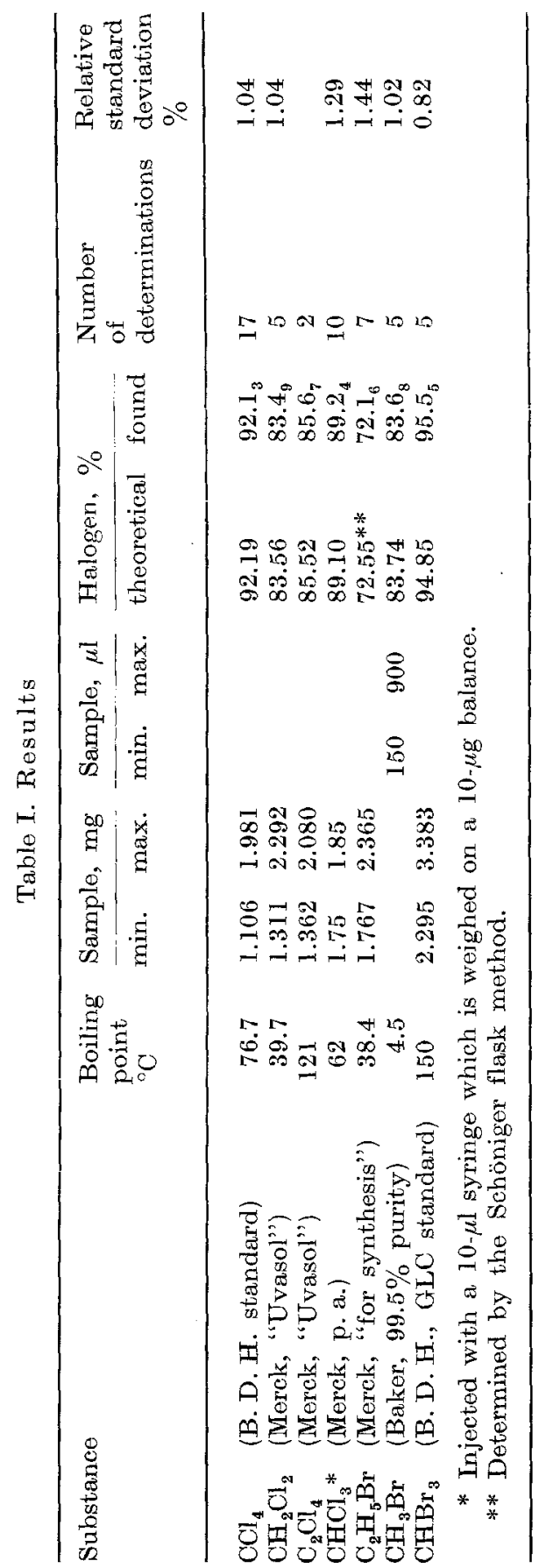




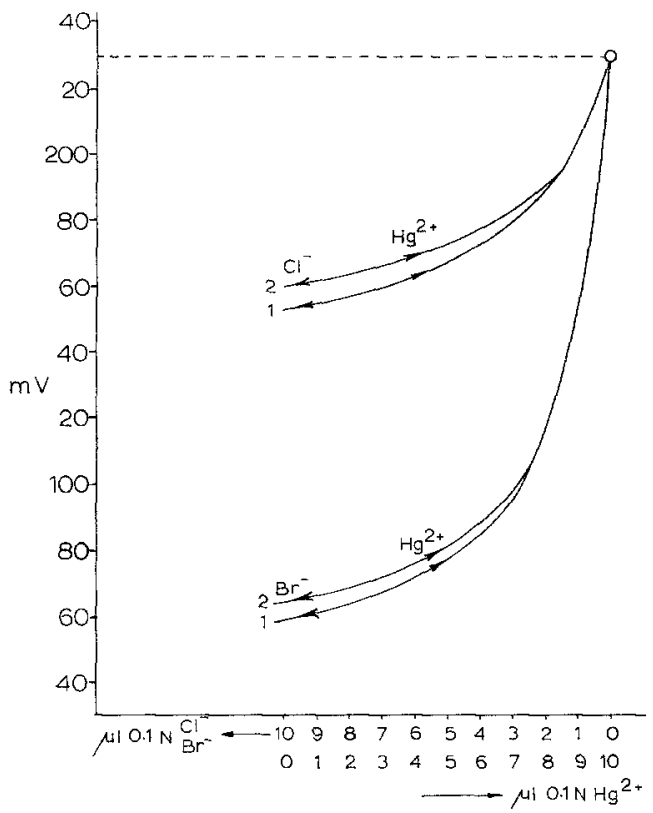

Fig. 6. Reversibility of the $\mathrm{Ag}_{2} \mathrm{~S}$ electrode with respect to $\mathrm{Cl}^{-}$and $\mathrm{Br}^{-}$in $95 \%$ acetic acid. The halide is back-titrated with $\mathrm{Hg}^{2}+$

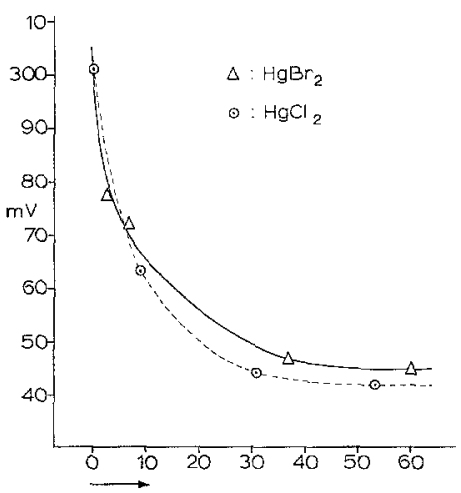

Fig. 7. Change in potential as a function of the $\mathrm{HgCl}_{2}$ and $\mathrm{HgBr}_{2}$ concentration in the initial absorption solution.

The use of reducing agents stronger than $\mathrm{H}_{2} \mathrm{O}_{2}$ in the absorption solution results in a reduction of the $\mathrm{Hg}^{2+}$ ions. If the concentration. of $\mathrm{H}_{2} \mathrm{O}_{2}$ is greater than $1.2 \% v / v$ then there is oxidation of the $\mathrm{S}^{2-}$ ions from $\mathrm{Ag}_{2} \mathrm{~S}$ the crystal. 
Titrations with $\mathrm{Hg}^{2+}$ with the use of solid-state silver halide electrodes have also been mentioned in the literature ${ }^{12,13}$. It was reported ${ }^{13}$ that the AgI electrode is more suitable for mercury than the $A g_{2} S$ electrode. Therefore, some determinations were carried out with the AgI electrode but it was found that the response time was very slow when compared to that of the $\mathrm{Ag}_{2} \mathrm{~S}$ electrode.

The maximum sensitivity and accuracy of the titration is about $0.03 \mu \mathrm{eq}$ of halide $/ \mathrm{mV}$. There is a linear relationship between the quantity of organic $\mathrm{Cl}$ combusted (up to $3 \mathrm{mg}$ ) and the quantity of $\mathrm{Hg}^{2+}$ required for the back-titration.

Some experiments were also made in an attempt to clarify the mechanism of the interaction of $\mathrm{Hg}^{2+}$ ions with the $\mathrm{Ag}_{2} \mathrm{~S}$ electrode. A I-electron Nernst slope of $60 \mathrm{mV}$ was observed with $\mathrm{Hg}^{2+}$. This behaviourt can be explained if it is assumed that the following ion-exchange process occurs on the surface of the $\mathrm{Ag}_{2} \mathrm{~S}$ crystal:

$$
\mathrm{Hg}^{2+}+\mathrm{Ag}_{2} \mathrm{~S}_{\text {(crystal) }} \rightleftharpoons[\mathrm{AgHgS}]^{+}{ }_{\text {(crystal) }}+\mathrm{Ag}^{+} \text {. }
$$

X-Ray fluorescence measurements carried out on the surface of an $\mathrm{Ag}_{2} \mathrm{~S}$ crystal showed that mercury can be detected after the crystal has been in contact for some time with a dilute $\mathrm{Hg}^{2+}$ solution. Before this measurement was made the crystal had been placed for some hours in $0.1 M$ EDTA and then rinsed with water and acetone. The intensity of the mercury signal is not affected even after treatment for several weeks with EDTA. Diffusion of mercury in the crystal does not occur. When the crystal surface is repolished with silicon carbide emery paper (number 400) the mercury response disappears.

\section{Acknowledgements}

The authors wish to thank Mr. M. Bos for his useful ideas and Mrs. L. Stefanova, and Messrs. H. Kruidhof and J.A.M. van Veen for their technical assistance. Philips N. V. Holland are also thanked for supplying a silver iodide electrode and a silver sulphide crystal.

\section{Summary}

Application of Ion-selective Electrodes for the Microdetermination of Chlorine and Bromine in Volatile Organic Compounds

A method is described for the determination of chlorine and bromine in $\mathrm{mg}$ samples of highly halogenated volatile organic compounds. The samples are introduced into the combustion system by injection and burnt in a stream of oxygen at $1000^{\circ}$ over platinum and quartz. The combustion gases are absorbed in a solution of $80 \%$ acetic acid containing some hydrogen peroxide, nitric acid and mercuric chloride or bromide. 
The halide is then titrated with mercury. The end-point is determined by an ion-specific electrode. One determination takes approximately 15 minutes. The relative standard deviation of the determination is about $1 \%$. The reversibility and durability of the silver sulphide electrode are unaffected as long as the mercury ion concentration is less than $10^{-3} \mathrm{M}$.

\section{Zusammenfassung}

Eine Methode für die Bestimmung von Chlor und Brom in Milligramm hochhalogenierter Substanzen wird beschrieben. Die Proben werden in das Verbrennungssystem eingespritzt und in einem Sauerstoffstrom bei $1000^{\circ} \mathrm{C}$ über Platin und Quarz verbrannt. Die Verbrennungsgase werden in $80 \%$ Essigsäure absorbiert, die etwas Perhydrol, Salpetersäure und Quecksilberchlorid oder -bromid enthält. Das Halogen wird mit einer Quecksilber(II)lösung titriert. Der Endpunkt wird mit Hilfe einer ionenspezifischen Elektrode ermittelt. Eine Analyse dauert etwa 15 Minuten. Die relative Standardabweichung ist $\pm 1 \%$. Die Reversibilität und Dauerhaftigkeit der Silbersulfidelektrode bleibt so lange unbeeinflußt, als die Konzentration der Quecksilberionen geringer ist als $10^{-3}-\mathrm{m}$.

\section{Résumé}

Une méthode pour le dosage du chlore ou du brome dans des échantillons milligramiques de composés organiques volatiles contenant des quantités élevées d'halogène a été décrite. Les échantillons sont introduits dans le système de combustion par injection et la combustion s'effectue sous courant d'oxygène à $1000^{\circ} \mathrm{C}$ sur platine et quartz. Les gaz de combustion sont absorbés dans une solution d'acide acétique $80 \%$ avec addition de faibles quantités de peroxyde d'hydrogène, acide nitrique et chlorure ou bromure mercurique. Puis l'haloide est titré avec une solution mercurique. Le point d'équivalence est établi à l'aide d'une électrode ion-spécifique. Un dosage prend approximativement 15 minutes et l'écart type est environ $1 \%$. La réversibilité et la durabilité de l'électrode de sulphure d'argent restent intactes pourvu que la concentration mercurique ne surmonte pas celle de $10^{-3} \mathrm{M}$.

\section{Literature}

1 H. Soep and P. Demoen, Microchem. J. 4, 77 (1960).

2 E. Debal and R. Levy, Mikrochim. Acta [Wien] 1964, 285.

3 R. Bennewitz, Mikrochim. Acta [Wien] 1960, 54.

4 W.J. Kirsten, Mikrochim. Acta [Wien] 1960, 272.

${ }^{5}$ E. Pella, Mikrochim. Acta [Wien] 1961, 472.

6 E. Pella, Mikrochim. Acta [Wien] 1965, 369.

7 J.C.Mamaril and C.E. Meleon, J. Chromatography 17, 23 (1965).

8 W. Krigsman, B.Griepinh, J.F. Mansveld, and W.J. van Oort, Mikrochim. Acta [Wien] 1970, 793.

${ }^{9}$ J.L. Swartz and T.S. Light, Tappi $\mathbf{5 3}$ (1), 90 (1970).

10 J. Papp and J.Havas, Proceedings of the International Measurement Confederation Symposium on Electrochemical Sensors. Veszprém, Hungary: 1968. p. 135.

11 J.Slanina, J.Agterdenbos, and B.Griepinh, Mikrochim. Acta [Wien] $1970,1225$.

12 J.L.Swartz and T.S. Light, Orion Newsletter 2 (7, 8), 36 (1970).

13 J.L.Swartz and T.S. Light, Orion Newsletter 2 (9, 10), 41 (1970). 